\title{
Uma forma breve esquecida: a praga da tradição oral portuguesa
}

\section{Carlos Nogueira*}

\begin{abstract}
Resumo: Máximo de emoção e significado num Abstract: Maximum of emotion and meaning in a mínimo de palavras, forma breve que é o sinal de um minimum of words, brief form or even microform espaço interior sem fim e de uma necessidade urgente which is the signal of an endless interior space and of de voz, a praga dá-se como um curto-circuito do an urgent necessity of voice, the curse is given as a pensamento de um sujeito que pratica uma alquimia de short circuit of the mind of a person that practices an palavras para agir sobre o real (que é muitas vezes - e o alchemy of words to act on reality (which is - and the enunciador sabe disso, consciente ou speaker knows that, consciously or not - his own inconscientemente - o seu próprio mundo visceral). $\quad$ visceral world).
\end{abstract}

Palavras-chave: Praga, oralidade, tradição.

Keywords: Curse, orality, tradition.

A praga, género do discurso a que o emissor recorre por tradicionalmente se the atribuir um poder mágico de destruição de um oponente, é ilegal e marginal, mesmo se é lei que salva quem o enuncia; porque, de acordo com a ortodoxia judaico-cristã, não passa de um texto herético, maldito, cuja natureza ético-moral é fortemente negativa e contrária ao pacifismo da mensagem de Cristo ${ }^{1}$.

A praga é uma maldição dinâmica e vitalista que nos coloca perante a evidência das raízes remotas do género e da sua disposição marcadamente antropológica e onto-existencial (a preservação do eu determina a eliminação violenta do outro), apesar do humor solto e mais ou menos inventivo que por vezes atenua os efeitos imediatos da mordacidade. Concretizemos com este "esconjuro", ou "conjuro", que tem a configuração da praga ou maldição em verso imediatamente reconhecível como tal; a única (e decisiva) diferença

\footnotetext{
* Centro de Tradições Populares Portuguesas "Prof. Manuel Viegas Guerreiro" - Universidade de Lisboa. carlos_nogueira@aeiou.pt

${ }^{1}$ Por isso mesmo, a "praga" é nomeada como um dos pecados maiores na "Oração para dizer na confissão": "Acuso-me, Senhor, da minha vida passada, juramentos falsos, pragas, mentiras, ofícios divinos, jejuns de igreja, faltas de missa, caridade, piedade (...)" (António Lourenço Fontes, Etnografia Transmontana. I: Crenças e Tradições de Barroso, 2. ${ }^{a}$ ed. corrigida e aumentada, s.e., Vilar de Perdizes / Montalegre, 1979 [1. ${ }^{a}$ ed., 1974], p. 70).
} 
relativamente à praga canónica é que o objecto da imprecação deste texto mágico-religioso é não uma pessoa mas $a$ entidade maior do universo do mal:

Foge de mim Lucifer/ que te esmago se eu quiser/ com pilão ou com colher/ para depois te comer/Va de retro Satanás/ que te meto no cabaz/ onde esmagado serás/ pelas pinças da tenaz/ vai à vida Belzebu/ mete os cornos no baú/ que te embrulho em pano-cru/ e te como com peru/ glu glu glu glu glu glu glu (VIEIRA, 2006, p. 7) ${ }^{2}$.

Enquanto micro-narrativa lírica que anuncia um fazer, organizada pela voz de um actante agressivamente satírico porque revoltado contra a submissão a que o querem reduzir, este poema é uma exemplar consubstanciação dos efeitos de ira de que se faz a circunstancialidade humana em que todos participamos. Se o que pela praga se persegue é a densificação de um mal, não é pois por acaso que se recorre a uma imagística do concreto disfemístico, a um arrebatamento semântico que necessita de um léxico paroxístico, de expressões sacudidas por sentimentos veementes, declarativos.

$\mathrm{O}$ ar de juventude daquela praga-esconjuro e do sujeito da enunciação, mortífero no seu mau humor mas também alegremente fescenino, assenta na estilística da repetição ${ }^{3}$ que por si só incute a energia, própria dos mais novos, que desgasta e vence pela saturação imposta ao outro pela acumulação dos mesmos signos linguísticos (o que está de acordo com a perspectiva infantil e juvenil que um Almada Negreiros persegue na sua obra). O processo de caricaturização (anulação) do objecto satirizado e amaldiçoado tem como circuito obsessivo um jogo linguístico e simbólico de intensificações. Sem esse registo energético que lhe induz sentido, sem o correspondente êxtase satírico que sublima o sujeito perante quem o afronta, a praga de nada vale.

Parece-nos óbvio que "esconjuro" não é um termo devidamente formalizado nos nossos estudos etnológicos, etnográficos e antropológicos, nem muito menos, ao contrário do que acontece em países como a Espanha e o México, nos nossos estudos literários; e, contudo, há na tradição oral portuguesa composições que transportam em si mesmas essa designação. Este texto - imperativo - é um esconjuro propriamente dito, mas não deixa de apresentar um elemento do ensalmo típico (a súplica a entidades superiores da religião católica): "Eu te esconjuro, diabo,/ Tista com tista;/ São Pedro e São Paulo/ E São João Baptista/ Em volta de

\footnotetext{
${ }^{2}$ Citamos a partir do texto de Alice Vieira Leandro, Rei da Helíria, que constitui "uma adaptação de uma

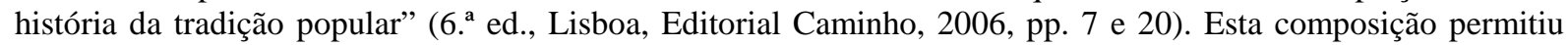
que Adélia Carvalho, com quem conversámos sobre este tema, evocasse uma versão ouvida várias vezes numa aldeia de Penafiel, distrito do Porto, a uma senhora septuagenária ainda viva.

${ }^{3}$ Pensamos nos três tipos de redundância do discurso poético a que se refere Jean Cohen (no artigo "Poesia e redundância", in O Discurso da Poesia (Poétique, n. ${ }^{\circ}$ 28), Coimbra, Livraria Almedina, 1982, pp. 53-67): a do signo (anáfora e refrão, por exemplo), a do significante (rima, metro, aliteração, assonância, etc.) e a do significado (como a sinonímia).
} 
mim assista./ Abrenuntia"4. Mas, por agora, queremos apenas dizer que é oportuno perguntar quantas vezes terão já estes textos sido usados com a função específica de praga dirigida a uma pessoa (Lucifer, bem como os inúmeros termos afins, pode valer como metáfora de qualquer nome).

É muito característico desta literatura mágica - arte proteiforme e combinatória que envolve, como toda a literatura oral e popular, um circuito de concepção, acomodação, recriação e reprodução - um processo de composição marcadamente sensorial que compensa com ameaças e coacções o vazio ou a retractação que a liturgia oficial, contemplativa e abstracta, impõe ao corpo e ao sensório no litígio com o outro. O que através da praga se vislumbra são as funduras do eu, a expansão dos conflitos de uma interioridade em busca de respostas para problemas sérios: a vertigem do eu perante as contingências que o rodeiam e perante a contingência que ele, em si mesmo, é.

Cada praga é ao mesmo tempo uma ameaça e uma sátira, um discurso de predação impiedosa de um adversário que deve sucumbir à força de palavras e gestos com poder sobrenatural. A energia satírica da praga é um modo extreme de resistência do sujeito da enunciação ao pessimismo e de estabelecimento da sua autodeterminação. Inscrita numa zona de radicalidade de um eu perdido num labirinto de sentimentos de raiva incontrolável, desencadeados por um oponente odioso, esta textualidade é, em si mesma, primeiro, causa e efeito do discurso: as propriedades ilocutórias do acto satírico de linguagem acabam por produzir uma pragmática de comunicação-interacção ao nível do próprio enunciador. Note-se, entretanto, que, certamente por ser de recolha muito sensível, este género tem sido pouco ou nada notado pelos recolectores e estudiosos que, sobretudo a partir de Teófilo Braga, se têm dedicado à investigação da literatura mágico-religiosa portuguesa. Trata-se, de facto, de um conjunto textual que, conotado com uma moralidade duvidosa ou inexistente, quem recolhe não tem por hábito procurar e quem informa esconde. A má reputação da praga vem desde logo de um princípio subentendido: o de se considerar o enunciador uma entidade do universo do mal. Isto é: o princípio subentendido de que o enunciador é uma entidade maléfica, ou alguém que estabelece pactos com o demoníaco, dá à praga uma má sina que a desloca para o campo mais privado e secreto do indivíduo ${ }^{5}$.

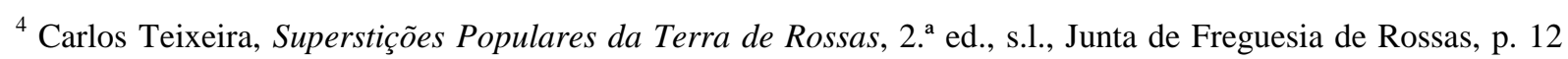
(1. ${ }^{\text {a }}$ ed., 1934).

${ }^{5}$ A obra de Margarida Tengarrinha Da Memória do Povo. Recolha de Literatura Popular de Tradição Oral do Concelho de Portimão é a única em que até agora deparámos com uma recolha de pragas (Lisboa, Edições Colibri, 1999, pp. 57-58). Devemos essa indicação ao nosso amigo José Joaquim Dias Marques, professor da Faculdade de Ciências Sociais e Humanas da Universidade do Algarve, que, numa carta que nos enviou, afirma:
} 
Para o agente, que, através da palavra, mata para punir e se salvar, a praga não é gratuita nem viciosa mas nem por isso interessará provar a legitimidade dessa violência junto do grupo. O texto vive na clandestinidade e portanto só ao sujeito importará, ou não, reconhecer-lhe inteireza moral (convencendo-se de que o oponente, autoritário e criminoso, não o pode acusar de imoralidades, ressentimento ou má-fé). A praga vive pois da conflitualidade que atravessa todos os recessos do quotidiano. A raiva imparável com que é proferida a forma mais breve desta especificidade textual - "Morre" (imperativo antecedido ou seguido muitas vezes de um vocativo insultuoso como "maldito" ou outros qualificativos que são palavrões) - mostra que se trata de uma manifestação extremada de energia natural e individual. Mas esta vinculação à ordem do contingente, pessoal e único, no sentido em que quem emite a praga é praticamente sempre um único emissor, animado por um substrato conjuntural e particular, não significa que a devamos caracterizar como anti-social. Constitui, bem pelo contrário, um mecanismo particularmente significativo de regulação da sociedade, uma voz de vozes, de que a interpretação coral do "Esconjuro contra os maridos transviados", a cargo do Coro Lopes-Graça e de muitos outros, é o paradigma literal e modelar:

Deus te salve, Sol divino!/ Tu corres o mundo inteiro;/ Viste lá o meu marido,/ Viste lá o meu marido?// Se tu o viste, não mo negues,/ Não mo negues, não negues, não./ Se tu o viste, não mo negues,/ Não mo negues, não negues, não.// Esses raios que vens deitando, ao teu nascimento,/ Sejam dores e facadas/ Que atravessem o seu coração.// Que ele por mim endoideça,/ Que ele não possa comer,/ Que ele por mim endoideça,/ Que ele não possa comer,// Nem beber, nem andar, nem amar,/ Nem com outra mulher falar./ Nem beber, nem andar, nem amar,/ Nem em casa particular!// Todas as mulher's qu'el'veja/ Lhe pareçam cabras negras e bichas feias./ Só eu lhe pareça bem no meio delas,/ Só eu lhe pareça bem no meio delas. ${ }^{6}$.

Esta é uma voz de inscrição violenta e contraditória no outro: o eu diz o mal porque lhe falta o bem, roubado pelo objecto da praga-esconjuro que é simultaneamente o objecto de desejo.

Como qualquer texto da literatura oral, a praga é histórica, irredutível a uma fixação: muda de acordo com o intérprete-autor, mas também de momento para momento e de comunidade para comunidade (ou de área para área), mesmo se há formulações em certa medida universais como "Havias de morrer", "Morto fosses tu aqui já", "Maldito sejas" ou

\footnotetext{
"A questão das pragas é um lugar-comum aqui no Algarve, sobretudo cada vez que se fala de Montegordo: há sempre quem saiba uma ou se lembre de ter ouvido, ainda que não se lembre. Mais complicado é, no entanto, encontrar textos publicados sobre o género ou mesmo colectâneas de pragas" (31 de Maio de 2007). Também Margarida Tengarrinha, a abrir a seç̧ão "Algumas pragas de Alvor", em que arrola sete textos, informa, depois de notar que «são incontáveis as chamadas "pragas" atribuídas aos pescadores de alvor (semelhantes às que se contam em Monte Gordo, Vila Real de S. ${ }^{\text {to }}$ António, Fuzeta e Olhão»: "Mesmo hoje, não é fácil conseguir de certos pescadores mais velhos o relato dessas pragas, dado que as levam a sério, como uma forma de maldição" (Da Memória do Povo cit., pp. 57-58).
}

\footnotetext{
${ }^{6}$ Recolha de Fernando Lopes-Graça, 1956.
} 
"Mil diabos te levem". Cada concretização é uma cerimónia mais ou menos clandestina em que um corpo visível combate um corpo inimigo visível e invisível ${ }^{7}$. Essa (in)visibilidade exige, por isso mesmo, uma contra-praga: "Bons olhos me vejam,/ bons olhos me protejam;/ Tu és ferro, eu sou aço,/ o mal que tu me desejas/ neste corno to embaço" ${ }^{\text {. }}$. Numa outra versão que pudemos coligir, os dois versos finais - "O mal que tu me queres/ que caia no teu regaço"9 - transformam mais o texto numa praga propriamente dita. Dir-se-ia que o inconfessável da primeira composição (um responso), ou seja, o mal que se quer impor ao outro, é revelado nesta ocorrência num misto de singeleza irónica e provocação. Quem profere o texto revela-se, na circunstância, um agente simultaneamente benéfico e maléfico, ou, numa perspectiva redutoramente maniqueísta, primeiro comprometido com uma acção benéfica e, no final, maléfica. Dizer que a praga é um sinal da maldade humana equivale a considerar que há bons e maus, inocentes e culpados. Por certo, a ninguém compete ajuizar sobre o grau de culpabilidade dos implicados no texto "Deus te dê em dobro tudo o que me desejas" 10 , com que se reage ironicamente a um cumprimento em cuja sinceridade não se acredita.

Às razões psicológicas do momento que activam a emissão da praga junta-se uma motivação orgânica de fundo: a preservação da integridade somática e psíquica do indivíduo que o obriga a uma actividade competitiva contínua com os outros. A praga é o signo-sinal, no sujeito, de um momento agonístico extreme: o combate que desencadeia no eu e no(s) outro(s) sentimentos de inquietação e angústia. Mas a crença em que se pode agir sobre uma pessoa através de palavras-acto é sobretudo um bem para o sujeito (ainda que ele possa confrontar-se com um sentimento de culpa, ou pelo menos com uma certa incomodidade, que vem da convicção de estar a acrescentar pecados ao pecado original e a contribuir para aumentar a miséria do ser humano perante Deus). Uma situação vivencial extrema pede um

\footnotetext{
7 "Hás-de morrer como um cão" e "Hás-de ter uma morte desgraçada" são dois textos que Donzília Ribeiro (nossa mãe), internada no Hospital Santos Silva (Vila Nova de Gaia), em Junho de 2007, pôde ouvir em três noites consecutivas, endereçados por uma senhora de 80 anos a uma enfermeira (que também os ouviu, tal era a raiva com que a emissora, natural de Valadares, Gaia, os proferia). Imediatamente reconhecemos o primeiro com duas variantes: "Hás-de morrer sozinho como um cão" e "Hás-de morrer sozinho como um cão com sarna".

8 Texto recolhido em Junho de 2007 por Adélia Carvalho, educadora no Colégio do Rosário (Porto). A informante, Emília Ribeira, educadora na mesma instituição de ensino, nascida em 1979, natural do Porto, notou que o texto é emitido em voz interior e com uma mão escondida, a fazer figas; e acrescentou que o aprendeu com a sua avó, natural de Trás-os-Montes.

${ }^{9}$ Recolha de Adélia Carvalho, que, no mesmo colégio do Porto referido na nota anterior, ouviu o texto a uma auxiliar de educação educativa, Manuela Antunes, nascida em 1978, natural de Matosinhos.

${ }^{10}$ Cf. a nota número 5 .
} 
acto de linguagem extremado: "Mil diabos a levem mais à barca que para cá a passou"11, diz o "Malhadinhas" de Aquilino Ribeiro, que também afirma, com humor derisório, num enunciado binário típico do provérbio, “Terçã o parta lá longe, que há-de morrer a dar coice!", 12 .

Essa crença, ou esse prazer de pensar e sentir que se pode mudar radicalmente o destino de alguém com o poder das palavras, estende-se, até, sobre alguém já morto, confirmando o maior dos males, na mitologia cristã ou Ocidental: “Arde no Inferno, maldito". Esta formulação, pertencente ao nosso repertório pessoal de pragas interiorizadas, como outras que aqui aparecem sem indicação de proveniência, é uma entre muitas variações do mesmo paradigma virtual, de uma mesma ideia-sentimento comum ao humano. Por isso, se este texto não é em absoluto rigor tradicional, deve pelo menos ser considerado colectivo. $\mathrm{O}$ texto só é tradicional se uma mesma expressão se mantém irredutível (como em "Deus te dê tantos anos de vida como de palmos tem uma formiga", enunciado que apresenta sem dúvida uma forma proverbial), ou se se desdobra comprovadamente sobre si mesma, permanecendo, não o primeiro texto, fixo e inviolável, o qual se diluiu nos que o perpetuam, mas o seu arquétipo, a sua memória instável.

Releve-se, também, que a praga pode ser um voto de destruição e morte endereçado directamente não ao corpo físico de um indivíduo mas a um qualquer universo de que ele é proprietário, como no "Responso de S. ${ }^{\text {ta }}$ Eufemia, que se diz ao rebanho para lhe causar dano": "Prò monte vás,/ Prà aldeia não venhas,/ Branquinha adiante,/ Pretinha atrás,/ Comamte os lobos,/ Espedacem-te os cães,/ A casa do teu dono nunca tornarás"; ou como no "Responso da ovelha ladrona": "Co rabo tapa a cona,/ Venha um lobo que a coma,/ Pra não voltar a casa da dona"13. Mais uma vez, há que observar que a praga por si só não autoriza uma leitura ética (em termos muito simples: alguém deseja o desaparecimento do rebanho porque ele danifica os seus produtos agrícolas ou apenas porque com isso quer prejudicar o seu dono?): só no contexto em que o texto surge é minimamente legítimo procurar definir a intencionalidade que o determina e assim inscrevê-lo, mesmo se muito provisoriamente, num quadro de Bem ou de Mal, de justo ou de injusto. Em termos genológicos, e porque nada nem ninguém pode garantir ao estudioso uma caracterização absolutamente rigorosa do contexto,

\footnotetext{
11 Em Quintela, concelho de Baião, identificámos a variante "Raios o partam mais à barca que para cá o passou" (Cândida da Conceição Nogueira, 53 anos. 28 de Junho de 2007).

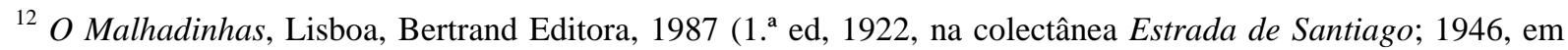
volume autónomo), pp. 82 e 102.

${ }^{13}$ António Lourenço Fontes, Etnografia Transmontana. I: Crenças e Tradições de Barroso cit., p. 71.
} 
composições como aquelas cabem por isso à partida nos conjuntos textuais recobertos quer pelo vocábulo "praga" quer pelos vocábulos, usados mais na linguagem dos especialistas, “ensalmo"14 e "esconjuro" ("reza" ou "benzedura”, na linguagem dos utilizadores).

A afirmação de denúncia e desagrado "Rogaram-me uma praga" (ou "Parece que me rogaram uma praga") legitima a convocação das potencialidades mágicas da palavra como defesa; e não custa deduzir que também autoriza uma reacção que só é nefasta do ponto de vista do moralismo oficial. Sobre a praga recai o peso da interdição mas isso não a torna minimamente associal. Inscrita numa cerimónia privada, as pragas mais usadas são às vezes ouvidas por receptores ocasionais (refiro-me a formulações breves como, para além das já aqui citadas, "Morto sejas/ fosses tu aí já", "Cego sejas / fosses tu”, "Oxalá morresses", "Oxalá partisses uma perna", ou, quando não é apenas uma interjeição que expressa uma reprimenda (séria ou simulada), "Raios te partam", em que a praga e o insulto se recobrem). Já as de elevado valor estético-performativo, de que há escassos registos, ou pelo menos as que nos surpreendem pelo inusitado do léxico e do conteúdo, podem ser transmitidas enquanto tal diferidamente, ou seja, fora do contexto que é parte imprescindível do ritual mágico específico de cada praga ("Mala ruína te caga nesses olhos" é um texto que um informante guarda na memória desde $1958^{15}$ ).

A praga concretiza-se muitas vezes num intenso poder de visualização que decorre em grande parte do adynato ou impossibile (uma das figuras retóricas por excelência da sátira propriamente dita e da praga, por permitir impor ao objecto satirizado uma série de causas e efeitos de excepção que atrai o leitor pela combinação de burlesco derisório e ficcionalização hiperbólica): "Amaldeçoade, havia de te dar uma dor tã grande ou tã pequena, que só passasse com o sumo da pedra" ou "Amaldeçoade, havia de te dar uma dor tã grande, tã grande, tã grande, que cabesse os alcatruzes todos que tem o mar dentro da tua barriga"16. Esta imaginística e estes ilogismos, esta estética do redimensionamento insólito das estruturas do real empírico, lembram-nos que à poética do oral e do popular nunca foi alheia a visão do

\footnotetext{
${ }^{14}$ Empregamos aqui o vocábulo com a plena consciência de que há um ensalmo típico (a cujas características aqueles dois textos não obedecem na íntegra): o emissor, que pode ser o beneficiário mas é geralmente o intermediário entre o sobrenatural e um padecente, invoca quase sempre uma entidade sagrada, com o objectivo de conseguir a resolução de um mal (a cura para uma doença) ou de um incidente (como a recuperação de um objecto perdido).

${ }^{15}$ Esta praga foi a resposta de uma cigana a Alexandre Nogueira (nosso pai), que, numa aldeia do concelho de Baião, lhe recusou a leitura da sina.

${ }^{16}$ Margarida Tengarrinha Da Memória do Povo. Recolha de Literatura Popular de Tradição Oral do Concelho de Portimão cit., p. 57.
} 
mundo e os procedimentos de linguagem que o Surrealismo explora e sistematiza; a, numa palavra, anamorfose surrealista.

$\mathrm{O}$ eco mais antigo, consistente e original da tradição da praga portuguesa em verso ${ }^{17}$ encontra-se, tanto quanto sabemos, em Gil Vicente. O género, dentro da metamorfose operada pela mestria do autor da Barca do Inferno (1517), conserva todos os elementos literários e antropológicos que fazem a sua especificidade: palavra que, como corpo estético e pragmático, total na sua brevidade, racional na sua voragem aparentemente só movida por uma vil e descontrolada irracionalidade, acontece com o fim de remir o enunciador, lançandoo, altivo e vitorioso, pelo menos no momento da proferição, sobre um oponente. Em Joane, uma das personagens vicentinas mais célebres, a invectiva endereçada sem eufemismos ao diabo cruza-se com a praga, sua alegação e seu lugar de prazer e repouso: "Tua molher é tinhosa/ e há de parir um sapo/ chentado no guardenapo/ neto de cagarrinhosa"18. Estes quatro versos são o emblema de um fundo indefinido de sensações e enunciados, o mais e o menos da outra linguagem que sempre fica sepultada num ruído ou num silêncio irredutíveis. A singeleza que de imediato se lhes reconhece não é ingenuidade: eles dizem a complexidade do comum ao humano (a manifestação verbal da ira, a preservação da integridade do eu), num discurso cuja semântica e prosódia se inscrevem na mais genuína tradição oral portuguesa. Em cada verso, robustamente edificado dentro das sete sílabas métricas, pontificam as recorrências vocálicas internas e finais, mas também os timbres fortes de consoantes como o /t/ e o /p/ ("Tua molher é tinhosa/ e há de parir um sapo"). Os versos tornam-se naturalmente memorizáveis porque esse micro-paralelismo fónico imprime uma musicalidade cadenciada e transparente às palavras. A desfiguração imparável do objecto, cuja condição arquidiabólica é ridicularizada através da mediocridade atribuída à sua mulher e à sua descendência anunciada (um sapo, animal grotesco), faz desta praga mínima, incrustada numa imprecação, um exemplo perfeito da modalidade que concentra a sua força no cómico de situação e de linguagem.

\footnotetext{
${ }^{17} \mathrm{O}$ que nos suscitou esta reflexão foi precisamente uma praga, assim denominada pelo intérprete e pelo entrevistador, que ouvimos numa edição do programa Lugar ao Sul, de Rafael Correia, transmitido, em Maio de 2007, na Antena 1. O texto, numa forma versificada que logo nos seduziu pela eufonia, convoca sobre o destinatário uma série de males físicos e espirituais, a concretizar pelo diabo mas também por animais, como cobras e escorpiões, que são reconhecidamente símbolos e agentes de morte afins daquela entidade demoníaca. Não reproduzimos aqui a composição porque não a pudemos fixar; e não obtivemos uma transcrição posterior porque, apesar dos esforços que desenvolvemos, não conseguimos contactar o autor do programa.

${ }^{18}$ Barca do Inferno, in As Obras de Gil Vicente, direcção científica de José Camões, vol. II, Lisboa, Centro de Estudos de Teatro da Faculdade de Letras da Universidade de Lisboa / Imprensa Nacional - Casa da Moeda, 2002, p. 537.
} 
Aquela praga não convoca personagens mágico-sagradas que acrescentem força ao poder psíquico do sujeito e à energia das palavras-rito por ele pronunciadas; nem isso se poderia esperar, porque o léxico e as imagens vulgares não se ajustam minimamente à nomeação do divino. Mas, como se sabe, há casos em que o enunciador, servindo-se de um protocolo de respeito e obediência, solicita a intervenção de entidades divinas, com o objectivo assumido de intensificar o tom injuntivo e autoritário do texto; é o que ocorre nesta praga-esconjuro, também uma contra-praga (diz-se a concluir: "esta praga donde veo/ Deos lhe apare negra vida"), que a velha de Quem Tem Farelos? (1505) profere invocando o auxílio de uma das mais elevadas figuras do Catolicismo e do próprio Deus desta religião:

Rogo à Virgem Maria/ que quem me faz erguer da cama/ que má cama e má dama/ e má lama negra e fria./ Má mazela e má courela/ mau regato e mau ribeiro/ mau silvado e mau outeiro/ má carreira e má portela.// Mau cortiço e mau sumiço/ maus lobos e maus lagartos/ nunca de pão sejam fartos/ mau criado, mau serviço./ Má montanha, má companha/ má jornada, má pousada/ má achada, má entrada/ má aranha, má façanha.// Má escrença, má doença/ má doairo, má fadairo/ mau vigairo, mau trintairo/ má demanda, má sentença./ Mau amigo e mau abrigo/ mau vinho e mau vezinho/ mau meirinho e mau caminho/ mau trigo e mau castigo.// Irá de monte e de fonte/ irá de serpe e de drago/ perigo de dia aziago/ em rio de monte a monte./ Má morte, má corte, má sorte/ má dado, má fado, má prado/ mau criado, mau mandado/ mau conforto te conforte.// Rogo às dores de Deos/ que má caída lhe caia/ e má saída lhe saia/ trama lhe venha dos céus./ Jesu que escuro que faz./ Oh mártere sam Sadorninho/ que má rua e que mau caminho/ cego seja quem m'isto faz.// Ui amara percudida/ Jesu a que m'eu encadeo/ esta praga donde veo/ Deos lhe apare negra vida. (VICENTE, 2002, pp. 165-166)

As acções e os estados nomeados em cada verso são convertidos em factos, no contexto de situação do poema, pela repetição anafórica dos adjectivos "mau" e "má" e pela enumeração. A acumulação ininterrupta desses procedimentos estilístico-estruturais é o sinal da auto-regeneração contínua dos males que hão-de alegadamente afectar o destinatário em todos os domínios da sua vida material e espiritual.

Num dos romances de imitação tradicional da novela $O$ Físico Prodigioso, enunciado pela multidão em fúria que assassina as personagens conotadas com o Santo Ofício, um máximo de organização prosódico-versificatória combina-se com um registo que progride geometricamente entre a mais ingénita e impetuosa agressividade contra o mundo e a mais dolorosa visão do mundo como calvário (patente no refrão constante a cada par de hemistíquios de 7 sílabas):

Morra o bispo e morra o papa,/ maila sua clerezia./ Ai rosas de leite e sangue,/ que só a terra bebia!/ Morram frades, morram freiras,/ maila sua virgaria./ Ai rosas de leite e sangue,/ que só a terra bebia!/ Morra o rei e morra o conde,/ maila toda fidalguia./ Ai rosas de leite e sangue,/ que só a terra bebia!/ Morram meirinho e carrasco,/ maila má judicaria./ Ai rosas de leite e sangue,/ que só a terra bebia!/ Morra quem compra e quem vende,/ maila toda a usuraria. /[...]/ Morram pais e morram filhos,/ maila toda a filharia./ [...]/ Morram marido e mulher,/ maila casamentaria. /[...]/ Morra amigo, morra amante,/ mailo amor que se perdia. /[...]/ Morra tudo, 
minha gente,/ vivam povo e rebeldia./ Ai rosas de leite e sangue,/ que só a terra bebia! (FIGUEIREDO, 1977, pp. 125-126)

A disciplina fónica decorre, como se vê, antes de mais, do rigoroso paralelismo simultaneamente sintáctico e lexical que estrutura todo o poema, e do paralelismo, também, no esquema rimático final, assonantado e monorrimo, em $i$ - $a$, pelo qual se quebra o efeito de ductilização que as simetrias rítmicas vão criando (cada dístico é uma unidade sintácticosemântica constituída por 15 sílabas métricas, pelo que a transcrição dos congéneres tradicionais se realiza, hoje, num único verso). A linguagem discursiva é convocada como mise-en-abîme da contundência do grito e do corpo, como energia material de uma interioridade que da dor de pensamento e de carne faz a perseguição e a dilaceração do objecto. E o riso demoníaco, operado no registo lírico do escárnio e do maldizer, é glorificado.

A praga em verso é uma máquina de subjectividade irredutível que organiza o caos de palavras e sentimentos do enunciador. O que há de mais íntimo no eu expressa-se na praga, metamorfose de uma sensibilidade que, pela palavra, aparece mais como pensamento do que como alucinação (principalmente se, como neste caso, o texto é relativamente extenso):

És engrata pra comigo:/ contra ti o tempo veijas,/ a fortuna de ti fuja,/ não logres o que deseijas.// Permita o Céu vingá'la sorte/ dos danos que me tens feito!/ Astrução tenhas no peito,/ não haja faca que corte,/ uma pinga de água-forte/ te dê alguém por castigo,/ quando comer's algum figo/ te arrebente a boca logo,/ Prò fato te salte o fogo,/ já que és engrata comigo!// Da mesa te fuja o prato,/ a panela se te apegue,/ nunca a soldada te chegue,/ piolhos tragas no fato,/ a loiça te quebre o gato,/ sempre malfadada sejas!/ Quando comeres cereijas,/ te dê logo uma degestão;/ em qualquer ocasião/ contra ti o tempo veijas!// Quando for's a ferir lume,/ mil pancadas dês nos dedos,/ sobre ti chovam penedos,/ cases com homem que fume,/ a casa te desarrume,/ andes sempre porca e suja,/ a todos pareças c'ruja,/ tão feia te vás fazendo!/ Digam todos em te vendo:/ a fortuna de ti fuja!// Quanto tiver's alguns pensares/ tos tirem do pensamento,/ quando tu fores, o vento/ a roupa que tiver's, levar,/ quando fores alguém chamar/ um par de surdos tu vejas,/ sempre malfadada sejas!/ Comas sempre o pão de rala,/ uma rouquidão te dê na fala,/ não logres o que desejas! (VASCONCELOS, 1979, pp. 482$483)^{19}$.

Entre o eu e o outro há um abismo intransponível que o texto testemunha e aprofunda. A convocação do divino valida a universalidade da individuação do poema ("Permita o Céu vingá'la sorte/ dos danos que me tens feito!’), que, nessa relação, exprime uma grandeza: a punição consiste na palavra justa e exacta e o eu potencia-se no interior da língua que cria para si próprio. O inumano (objecto) transforma-se no mais humano (sujeito).

Resta-nos, para já, arriscar a afirmação de que subsiste na tradição oral portuguesa um género, por certo apreciável na quantidade e na qualidade dos seus tipos e respectivas

\footnotetext{
${ }^{19}$ Este texto é o único da rubrica n. ${ }^{\text {12 }}$ 12, intitulada "Pragas", incluída no capítulo XXXI - Assuntos vários versados em décimas. Sem indicação do local de recolha.
} 
variantes, com valor intrinsecamente performativo, quer dizer, investido de força estética, ritual e pragmática, cuja designação que melhor o nomeia (praga) é também o que primeiro o esconjura (afastando-o das colectâneas de literatura oral, tradicional e popular, e da área de investigação de especialistas); mesmo se é de crer que a praga constitui, no essencial, como sucede com a congénere da literatura dita $\operatorname{culta}^{20}$, energia pura e vital contra a frustração e a derrota, e evita certamente males piores: a degeneração do sofrimento do emissor em doença psicossomática; a violência física e psicológica exercida sobre alguém inocente e/ou culpado; e o corte de relações, até entre pessoas do mesmo grupo familiar, motivado por um equívoco que a praga, nas suas valências curativas ou pacificadoras, resolve (o melhor da praga, para o sujeito, pode ser mesmo a sua vertente de purificação, autognose e ética; purificação, sublinhe-se, enquanto libertação de energias negativas, não necessariamente enquanto expurgação do mal do enunciador).

\section{Referências}

COHEN, Jean. Poesia e redundância. O Discurso da Poesia . Coimbra: Livraria Almedina, 1982, pp. 53-67.

FIGUEIREDO, Tomaz de. Malho Rodeiro. In: Poesia I, Lisboa: Imprensa Nacional - Casa da Moeda, 2003.

. O físico prodigioso. Lisboa: Edições 70, 1977.

FONTES, Lourenço. Etnografia Transmontana. I: Crenças e Tradições de Barroso, 2. ed. corrigida e aumentada, s.e., Vilar de Perdizes / Montalegre: 1979 (1. ${ }^{\text {e ed., 1974). }}$

\footnotetext{
${ }^{20}$ Exorcizar um mal é, muitas vezes, mais do que um gesto de libertação, querer impor um mal a esse mal, como neste "Exorcismo" de Jorge de Sena: "Ó cães da morte, que me uivais, mordeis!/ Humanos-infra, que sois morte e cães!/ Va de retro, Satana, requiem aeternam/ terei sem vos ouvir, nem mesmo ao chiar/ de mijo nos meus ossos, quando alçardes perna./ Cães cães de cães e vossos fillhos cães/ que filhos cães de cães gerarão cães:/ haveis de ouvir-me até depois de mortos/ e cisco e lama num ranger de dentes:/ e os cães de cães de vossos filhos cães/ por mais que me uivem hão-de ouvir também/ a voz humana que vos foi negada,/ va de retro, Satana, abracadabra (40 Anos de Servidão, 2. ${ }^{\mathrm{a}}$ ed. revista, Lisboa, Morais Editores, 1982 (1. a ed., 1979), p. 124). Nós podemos designar de "praga" aquilo a que o emissor chama "exorcismo": o que nos interessa é a função do texto, não a sua moralidade positiva ou negativa (que, como dissemos, não compete avaliar aos não implicados nesse jogo de morte). Eis o que também caracteriza este texto de Tomaz de Figueiredo, igualmente intenso na imposição ao adversário de uma violência verbal e oracular com poderes de transformação-anulação projectiva do corpo que se rejeita: "Maldito seja, mil milhões de vezes,/ cem mil milhões, esse a quem devo isto!/ Que o não redima a ele o amor de Cristo,/ e que a sua alma se requeime em fezes!// Que, no inferno, mais do que chineses/ suplícios, de diabólicos registos,/ lhe retalhem do mal os negros quistos:/ seja-lhe o instante um bilião de meses.// - Demónios, espetai-o, espicaçai-o!/ o maior dos tormentos, inventai-o,/ dai-lho, porque ao pé dele vós sois santos.// Que ao menos ele sofra um nada, a sombra/ deste sofrer que a minha alma assombra:/ lume lhe seja a água dos meus prantos" (Malho Rodeiro, in Poesia I, Lisboa, Imprensa Nacional - Casa da Moeda, 2003, p. 362). Se escrever assim é matar, não deixa de ser, também, matar-se.
} 
RIBEIRO, Aquilino. O Malhadinhas. Lisboa: Bertrand Editora, $1987^{21}$

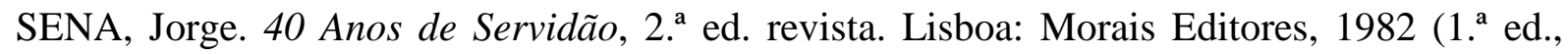
1979).

TEIXEIRA, Carlos. Superstições Populares da Terra de Rossas, 2. ${ }^{\text {a }}$ ed., s.1., Junta de Freguesia de Rossas, s.d. (1. ${ }^{a}$ ed., 1934).

TENGARRINHA, Margarida. Da Memória do Povo. Recolha de Literatura Popular de Tradição Oral do Concelho de Portimão. Lisboa: Edições Colibri, 1999.

VASCONCELOS, José Leite de. Cancioneiro Popular Português. NUNES, Maria Arminda Zaluar (Coord. e introd.). Coimbra: Acta Universitatis Conimbrigensis, Por Ordem da Universidade, 1979. v.II.

VICENTE, Gil. As Obras de Gil Vicente. CAMÕES, José, (dir.). Lisboa: Centro de Estudos de Teatro da Faculdade de Letras da Universidade de Lisboa / Imprensa Nacional - Casa da Moeda, 2002. v.II

VIEIRA, Alice. Leandro, Rei da Helíria. 6. ${ }^{\mathrm{a}}$ ed. Lisboa: Editorial Caminho, 2006

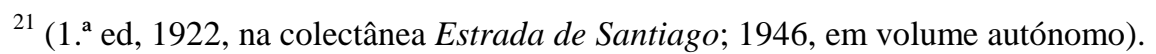

